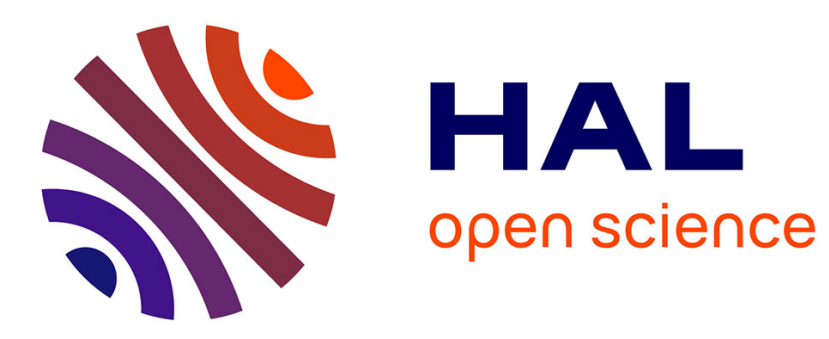

\title{
3D mathematical modelling to understand atypical heat transfer observed in vial freeze-drying
}

Bernadette Scutellà, Artemio Plana-Fattori, Stéphanie Passot, E Bourlès, Fernanda Fonseca, Denis Flick, Ioan-Cristian Trelea

\section{- To cite this version:}

Bernadette Scutellà, Artemio Plana-Fattori, Stéphanie Passot, E Bourlès, Fernanda Fonseca, et al.. 3D mathematical modelling to understand atypical heat transfer observed in vial freeze-drying. Applied Thermal Engineering, 2017, 126, pp.226 - 236. 10.1016/j.applthermaleng.2017.07.096 . hal-01582545

\section{HAL Id: hal-01582545 \\ https://hal.science/hal-01582545}

Submitted on 6 Sep 2017

HAL is a multi-disciplinary open access archive for the deposit and dissemination of scientific research documents, whether they are published or not. The documents may come from teaching and research institutions in France or abroad, or from public or private research centers.
L'archive ouverte pluridisciplinaire $\mathbf{H A L}$, est destinée au dépôt et à la diffusion de documents scientifiques de niveau recherche, publiés ou non, émanant des établissements d'enseignement et de recherche français ou étrangers, des laboratoires publics ou privés. 
3D mathematical modelling to understand atypical heat transfer observed in vial freeze-drying

Authors: B. Scutellà ${ }^{1,2}$, A. Plana-Fattori ${ }^{3}$, S. Passot ${ }^{1}$, E. Bourlès ${ }^{2}$, F. Fonseca ${ }^{1}$, D. Flick ${ }^{3}$, I.C. Trelea $^{1}$

${ }^{1}$ UMR GMPA, AgroParisTech, INRA, Université Paris Saclay, 78850 Thiverval-Grignon, France

${ }^{2}$ GSK Vaccines, Rixensart, Belgium

${ }^{3}$ UMR Ingénierie Procédés Aliments, AgroParisTech, INRA, Université Paris-Saclay, 91300 Massy, France 


\begin{abstract}
In pharmaceutical freeze-drying, the position of the product container (vial) on the shelf of the equipment constitutes a major issue for the final product quality. Vials located at the shelf edges exhibit higher product temperature than vials located at the centre, which in turn often results in collapsed product. A physics-based model was developed to represent heat transfer phenomena and to study their variation with the distance from the periphery of the shelf. Radiation, conduction between solids, and conduction through low-pressure water vapour were considered. The modelling software package COMSOL Multiphysics was employed in representing these phenomena for a set of five vials located at the border of the shelf, close to the metallic guardrail. Model predictions of heat fluxes were validated against experimental measurements conducted over a broad range of shelf temperatures and chamber pressures representative for pharmaceutical freeze-drying. Conduction through low-pressure water vapour appeared as the dominant mechanism explaining the additional heat transfer to border vials compared to central ones. The developed model constitutes a powerful tool for studying heterogeneity in freeze-drying while reducing experimental costs.
\end{abstract}

\title{
Highlights:
}

- A 3D mathematical model of heat transfer in freeze-drying is proposed.

- The role of several heat transfer mechanisms is explored.

- Knudsen effect is considered for conduction inside low-pressure water vapour.

- Radiation heat transfer is evaluated using the surface-to-surface model.

- Atypical heat transfer is explained mainly by gas conduction rather than radiation.

Keywords: lyophilization, edge vial effect, radiation heat transfer, Knudsen conduction, low-pressure gas, vacuum heat transfer. 


\section{NOMENCLATURE}

$\begin{array}{ll}A & \text { Area }\left(\mathrm{m}^{2}\right) \\ e & \text { Emissivity } \\ F & \text { Visualization factor } \\ \Delta H & \text { Latent heat of sublimation }\left(\mathrm{Jg}^{-1}\right) \\ j & \text { Mass flow rate }\left(\mathrm{kg} \mathrm{s}^{-1}\right) \\ K & \text { Heat transfer coefficient }\left(\mathrm{W} \mathrm{m}^{-2} \mathrm{~K}^{-1}\right) \\ l & \text { Thickness }(\mathrm{m}) \\ m & \text { Mass of the vial }(\mathrm{kg}) \\ P & \text { Pressure }(\mathrm{Pa}) \\ \dot{Q} & \text { Heat flow rate }\left(\mathrm{J} \mathrm{s}^{-1}\right) \\ q & \text { Heat flux }\left(\mathrm{J} \mathrm{m}^{-2} \mathrm{~s}^{-1}\right) \\ T & \text { Temperature }\left({ }^{\circ} \mathrm{C}\right) \\ t & \text { Sublimation time }(\mathrm{s})\end{array}$

\section{Greek symbols}

$\alpha \quad$ Semi-empirical constant

$\delta \quad$ Average vial bottom concavity thickness $(m)$

$\Lambda_{o} \quad$ Free molecular flow heat transfer coefficient $\left(W \mathrm{~m}^{-2} \mathrm{~K}^{-1} \mathrm{~Pa}^{-1}\right)$

$\lambda \quad$ Thermal conductivity $\left(W m^{-1} K^{-1}\right)$

$\sigma \quad$ Stefan-Boltzmann constant $\left(W \mathrm{~m}^{-2} K^{-4}\right)$

\section{Subscripts}

$\begin{array}{ll}1,2 & \text { Body } 1 \text { and } 2 \\ B S & \text { Bottom shelf } \\ B V & \text { Bottom vial } \\ c & \text { Heat transfer by conduction (general) } \\ C & \text { Chamber } \\ c c & \text { Heat transfer by contact conduction between solids } \\ C V & \text { Contact between the shelf and the vial } \\ G & \text { Glass } \\ i & \text { Interface } \\ I & \text { Ice }\end{array}$

IN, FIN Before and after sublimation 


$\begin{array}{cl}K n & \text { Knudsen } \\ r & \text { Heat transfer by radiation } \\ R & \text { Rail } \\ S & \text { Shelf } \\ T S & \text { Top shelf } \\ V & \text { Vial } \\ W & \text { Wall } \\ w & \text { Water vapour }\end{array}$




\section{Introduction}

Freeze-drying is a drying process involving three successive steps: freezing of the aqueous solution, followed by primary drying to remove ice by sublimation and, finally, secondary drying to remove unfrozen or sorbed water [1]. Due to the very low temperatures involved, freeze-drying process is particularly suitable for preservation of a wide variety of heatsensitive products such as high-value foods, cultured microorganisms, pharmaceuticals and nanoparticles [2-5]. This work is focused on pharmaceutical products (e.g. vaccines, proteins, peptides), which are usually processed in small containers (vials) loaded on the shelf of the equipment. During the primary drying step, the total heat transfer towards the sublimation interface is mainly dependent on the operating parameters (shelf temperature, chamber pressure, step duration), but also on the vial geometry and on the position of the vial on the shelf [6-9]. Vials located at the periphery of the shelf (named edge vials) receive an additional heat flow and present a product temperature up to $4{ }^{\circ} \mathrm{C}$ higher compared to vials located in the centre of the shelf (named central vials) and surrounded only by other vials at the same conditions $[6-8,10]$. This atypical heat transfer characteristic is usually known as "edge vial effect" [7].

The "edge vial effect" represents a serious issue in process control because it causes variability in terms of heat flow and product temperature in the vial batch [7]. If product temperature exceeds a critical value (e.g. glass transition temperature for amorphous products) the product will lose its porous structure and then will collapse [11-15]. Due to the additional heat flow received and the higher product temperature, collapse can take place in vials located at the periphery of the shelf rather than in central vials. For this reason, the understanding of the mechanisms causing the heat flow variability with respect to the position of the vial on the shelf is a key point for a successful process design.

Several mono- and multi-dimensional mathematical models of freeze-drying were developed in the past years [16-25], but only few of them explore the sources of the atypical heat flow rate in edge vials. In most of the studies [19,20,22,25], the heat transfer by radiation from the door and walls of the drying chamber was considered completely responsible of the higher product temperature observed in edge vials. However, Gan et al. [18] and Rambhatla et al. [7] showed that the presence of the metallic rail surrounding vials also contributes to the heat transfer by means of contact conduction and radiation.

Due to the very low pressures used during the process, the conduction through the gas in freeze-drying partly takes place under Knudsen regime and it is thus dependent on the chamber pressure. Recently, a study of Pikal et al. [8] showed that the conduction through the 
low-pressure water vapour contained in the gap between the metallic rail and the vial could play a relevant role in the additional heat transfer in edge vials.

The main objective of this work was to develop a 3D mathematical model in order to (i) predict the heat flow received by the vials located at the border of the shelf under different operating conditions and (ii) assess the relative importance of the involved mechanisms in the heat transfer, with particular attention to the radiation heat transfer and conduction through the low-pressure water vapour present in the drying chamber. The COMSOL Multiphysics software was used to design a 3D mechanistic mathematical model of the heat transfer during the sublimation step of the freeze-drying process. The geometry was defined to represent a portion of the drying chamber, including metallic rail, shelves, wall and an array of five vials. The presence of the gas in the drying chamber was considered and an original approach was used to represent the heat transfer through the gas in Knudsen regime near solid surfaces. The model was then validated with experimental data obtained from sublimation tests performed in a pilot scale freeze dryer at two shelf temperatures $\left(-40{ }^{\circ} \mathrm{C}\right.$ and $\left.0{ }^{\circ} \mathrm{C}\right)$ and four chamber pressures $(4,6,9,15 \mathrm{~Pa})$ covering the usual range of conditions in pharmaceutical freezedrying. Then, the contributions of the individual heat transfer mechanisms were quantified specifying the effect of chamber walls, rail and shelves.

The developed model predicted in an accurate way the heat flow rates in edge and central vials and can be used for investigating different vials loading configurations and the impact of equipment design.

\section{Materials and Methods}

\subsection{Materials}

The experimental determination of the sublimation heat flow rates was carried out on a pilot freeze-dryer (LyoVac GT6 Finn-Aqua Santasalo-Sohlberg SPRL, Bruxelles, Belgium; Figure 1A). This equipment had 5 shelves with an area of $0.14 \mathrm{~m}^{2}$ each. The distance between shelves was $62 \mathrm{~mm}$ whereas the distance between shelf and wall was $55 \mathrm{~mm}$. Measurements of the shelf, wall and rail emissivity were performed by Themacs Ingénierie (Champs sur Marne, France) using the emissometer EM-2 [26]. The measured values are reported in Table 1.

Glass siliconized tubing vials ( $3 \mathrm{~mL}$, Müller \& Müller, Holzminden, Germany) filled with 1.8 $\mathrm{mL}$ of distilled water were used. A detailed dimensional analysis of vial geometry was performed on a batch of 120 vials by a specialized company Precis\&Mans (Le Mans, 
France), using the micrometer Mitutoyo 3D (accuracy $\pm 0.003 \mathrm{~mm}$; Mitutoyo Europe GmbH, Neuss, Germany).

The pressure in the freeze-dryer chamber was monitored and controlled by a capacitive manometer. A number of six temperature wireless sensors (Tempris IQ Mobil Solution $\mathrm{GMbH}$, Holzkirchen, Germany) were positioned in the bottom centre of selected vials to record ice temperature during the experiments (Figure 1B). In some tests, the temperatures of the drying chamber wall was measured by sticking additional sensors by means of aluminium tape. The values of the wall temperatures measured for shelf temperatures of $-40{ }^{\circ} \mathrm{C}$ and $0{ }^{\circ} \mathrm{C}$ are reported in Table 1.

\subsection{Sublimation heat flow evaluation}

The sublimation heat flow was experimentally determined by following the method previously described by Scutellà et al. [9]. A number of 540 vials in hexagonal arrangement were loaded on the middle shelf of the freeze-dryer pre-cooled at $-50{ }^{\circ} \mathrm{C}$ using a bottomless tray. Vials were directly in contact with the shelf and surrounded by a stainless steel rail, as shown in Figure 1. After a freezing step of 2 hours, the pressure was decreased and the shelf temperature was increased at a rate of $1{ }^{\circ} \mathrm{C} / \mathrm{min}$ to the set point. Six sublimation tests in total were carried out: four at the shelf temperature of $0{ }^{\circ} \mathrm{C}$ and chamber pressures of $4,6,9,15$ $\mathrm{Pa}$ and two at the shelf temperature of $-40{ }^{\circ} \mathrm{C}$ and chamber pressures of 4 and $6 \mathrm{~Pa}$. The cycle was allowed to run long enough to sublimate up to $20-25 \%$ of the initial mass of water. Subliming a larger quantity of the ice may lead to loss of contact between the vial and the ice, introducing uncertainty in the analysis.

The sublimation rates were measured gravimetrically. As reported by Pisano et al. $[27,28]$, the vials located after the second row from the border of the shelf can be considered as equivalent to central vials. Thus, a number of 100 central vials (named $\mathrm{M}$ in Figure 1B) and 62 edge vials, among which 38 were in contact (C vials in Figure 1B) and 24 were not in contact with the rail (E vials in Figure 1B), were weighed before and after the run using a PG503-S DeltaRange balance (accuracy \pm 0.001g; Mettler Toledo, Zaventem, Belgium).

After the sublimation tests, the mass flow rate $j$ was calculated as:

$$
\dot{J}=\frac{m_{I N}-m_{F I N}}{t}
$$

Equation 1 
where $m_{I N}$ and $m_{F I N}$ are the initial and final masses of the vial and $t$ is the sublimation time measured from the moment when shelf temperature exceeded the product temperature, meaning that there was a net heat flux from the shelf towards the vials.

In freeze-drying, pseudo-stationary state can be assumed because of the slow dynamics of the process $[6,23,27,29]$. Under this condition, the net heat flow rate $\dot{Q}$ at the sublimation interface is directly proportional to the mass flow rate $\dot{j}$ :

$$
\dot{Q}=\Delta H \dot{j}
$$

Equation 2

$\Delta H$ being the latent heat of sublimation (Table 1).

\section{Mathematical model}

\subsection{Geometry}

The 3D geometry, representing a portion of the drying chamber, was built in COMSOL Multiphysics (Figure 2A). It included wall, rail, bottom and top shelves and five vials. The geometry was considered to be symmetric about the $\mathrm{x}-\mathrm{z}$ plane. Figure $2 \mathrm{~B}$ focuses on the hexagonal arrangement of vials, which were placed in direct contact with the bottom shelf. The vials located at the border of the shelf were alternatively in contact (vial C) and not in contact (vial E) with the rail.

The detailed vial and rail geometry is presented in Figure 2C. All the vials were made of borosilicate glass and were filled with pure ice. The vial bottom was designed to have an area in contact with the shelf and a cylindrical concavity. The thickness of this concavity $\delta$ was considered equal to the mean bottom curvature depth calculated by Scutellà et al. [9] $(0.12$ $\mathrm{mm})$.

\subsection{Problem statement and boundary conditions}

In this model, heat transfer during pure ice sublimation was simulated. A flat ice-vapour interface and a constant ice thickness were defined. The drying chamber was considered to be completely saturated with vapour water during sublimation [5]. The temperatures of several surfaces were imposed: (i) the top and bottom shelves temperature, imposed as operating condition; (b) the wall temperature, determined from experimental data; (c) the ice-vapour interface temperature $T_{i}$, evaluated from the Clausius-Clapeyron relation [23]:

$$
T_{i}=\frac{6139.6}{28.8912-\ln \left(P_{i}\right)}
$$


where $P_{i}$ was taken equal to the chamber pressure since no mass transfer resistance between the ice-vapour interface and the chamber was considered.

During the process, several sources contribute simultaneously to the heat transfer toward the sublimation interface. The main heat transfer mechanisms and their characteristic coefficients are schematized in Figure 3 and can be synthesized as follows:

a) Conduction through the gas in the drying chamber. A fictitious layer was defined, named Knudsen layer, which covers all the solids (i.e. ice, vial glass, rail, wall, top and bottom shelves), represented as a violet bold line in Figure 3. The thickness of the Knudsen layer $l_{K n}$ was arbitrarily set to be equal to $1 / 4$ of the vial glass thickness;

b) Conduction between solids. Only the conductive exchanges which were expected to be the most relevant were considered, i.e. (i) the conduction between the bottom shelf and the vials $\left(K_{c c_{V}}\right)$ and (ii) the conduction between the bottom shelf and the rail $\left(K_{c c_{R}}\right)$;

c) Radiation. A number of radiation fluxes were taken into account, as shown in Figure 3:

- from the top $\left(F_{T S \rightarrow V}\right)$ and bottom shelves $\left(F_{B S \rightarrow V}\right)$ to the vials;

- from the top shelf to the rail $\left(F_{T S \rightarrow R}\right)$;

- from the chamber wall to the rail $\left(F_{W \rightarrow R}\right)$ and to the parts of the vials which face the wall $\left(F_{W \rightarrow V}\right)$;

- between the rail and the vials $(\mathrm{E}$ and $\mathrm{C})$ facing it $\left(F_{R \rightarrow V}\right)$;

- between the vial internal walls and the ice $\left(F_{I \rightarrow V}\right)$.

Heat transfer by convection was not considered in the model. Even if a debate is ongoing in literature on the importance of convection during freeze-drying [7,8,30], a recent work of Pikal et al. [8] has shown that convection can be considered negligible at the low pressures typically encountered during the freeze-drying of pharmaceuticals (usually below $10 \mathrm{~Pa}$ ).

Under those hypotheses, modelling heat transfer in freeze-drying involved the simultaneous solution of conduction in solid, in gas and radiation heat transfer equations.

\subsection{Heat transfer by conduction}

The heat transfer by conduction occurring inside different materials (i.e. vial glass, ice, rail, gas) was described by the first Fourier law [31]:

$$
\vec{q}_{c}=-\lambda \nabla T
$$

Equation 4 
$\vec{q}_{c}$ being the heat flux, $\nabla T$ the temperature gradient and $\lambda$ the thermal conductivity of the materials, reported in Table 1.

\subsubsection{Thermal conductivity of the gas in the drying chamber}

Usually freeze-drying of pharmaceuticals is carried out at very low chamber pressure, in a range of 4 to $10 \mathrm{~Pa}$. Under this condition, the density of the gas is very low and the gas molecules collide more frequently with solid surfaces than among them at distances from the solid surface lower than the free molecular path (equal to about $0.6 \mathrm{~mm}$ at $10 \mathrm{~Pa}$ for water vapour) [29]. Thus, in typical ranges of freeze-drying operating parameters (i.e. chamber pressure $<10 \mathrm{~Pa}$ and shelf temperature $<0{ }^{\circ} \mathrm{C}$ ), the heat transfer regime is classified as the free-molecular or Knudsen regime near solids surfaces [6,21,29,32]. In the present model, the heat transfer under Knudsen regime was simulated by building a fictitious layer (named Knudsen layer) around all solids in contact with gas, as previously described (§3.2).

According to previous works of Pikal et al. [6,29], the heat transfer by conduction through the water vapour during freeze-drying can be described as:

$$
q_{w}=K_{w}\left(T_{1}-T_{2}\right)
$$

where $q_{w}$ is the heat flux by conduction through the water vapour, $T_{1}$ and $T_{2}$ are respectively the temperatures of the two solids between which the gas is contained and $K_{w}$ is the global heat transfer coefficient by conduction through the water vapour.

The global resistance to heat transfer through the gas $\left(\frac{1}{K_{w}}\right)$, as described in the model and shown in Figure 4, can be defined as [6,29]:

$$
\frac{1}{K_{w}}=\frac{l_{w}}{\lambda_{w}}+2 \frac{l_{K n}}{\lambda_{K n}}
$$

In Equation 6, $l_{w}$ is the distance among the two solid surfaces between which the gas is contained, $\lambda_{w}$ is the water vapour thermal conductivity, $l_{K n}$ is the Knudsen layer thickness whereas $\lambda_{K n}$ is the Knudsen layer conductivity. The resistance to the heat transfer in the Knudsen layers $\left(2 \frac{l_{K n}}{\lambda_{K n}}\right)$ was defined by Pikal et al. [6,29] as:

$$
2 \frac{l_{K n}}{\lambda_{K n}}=\frac{1}{\alpha \Lambda_{o} P_{C}}
$$


where $\alpha$ is a semi-empirical constant related to the quality of energy exchange between the solid surface and the gas and usually estimated by regression from experimental data, $\Lambda_{\mathrm{o}}$ is the free molecular flow heat transfer coefficient and $P_{C}$ is the chamber pressure. In the present work, the coefficient $\alpha$ was determined considering experimental data of sublimation tests presented by Scutellà et al. [9] (where $\alpha=C_{2} / \Lambda_{o}$, with $C_{2}$ equal to 0.67). The determined $\alpha$ value and other relevant parameters for heat transfer modelling are reported in Table 2.

Thus, the thermal conductivity of the Knudsen layer $\lambda_{K n}$ was estimated from Equation 7 as follows:

$$
\lambda_{K n}=2 \alpha \Lambda_{o} P_{C} l_{K n}
$$

Equation 8

\subsection{Heat transfer by contact conduction between solid bodies}

The heat flux by contact conduction between two bodies in contact (e.g. vial-shelf or railshelf, Figure 3) can be defined as [6]:

$$
q_{c c}=K_{c c}\left(T_{1}-T_{2}\right)
$$

Equation 9

where $q_{c c}$ is the heat flux from body 1 to body 2 transmitted by contact conduction, $T_{1}$ and $T_{2}$ are respectively the temperatures of the two bodies and $K_{c c}$ is the heat transfer coefficient by contact conduction, which depends on the quality of the contact. The heat transfer coefficient by contact conduction between the shelf and the vial $\left(K_{c c_{V}}\right)$ was evaluated from the work of Scutellà et al. [9]: a coefficient $K_{c}$ (equal to $3.67 \mathrm{~W} \mathrm{~m}^{-2} \mathrm{~K}^{-1}$ ) was evaluated, with reference to the entire vial bottom area $\left(A_{B V}\right)$. In order to obtain the heat transfer coefficient by contact conduction applicable to the contact area only $\left(A_{C V}\right), K_{c c_{V}}$ was considered equal to $K_{C} \frac{A_{B V}}{A_{C V}}$. In contrast, the heat transfer coefficient by contact conduction between shelf and rail $\left(K_{c c_{R}}\right)$ was determined by fitting model predictions to the rail temperature measured in a separate experiment. The values of these coefficients are reported in Table 2.

\subsection{Heat transfer by radiation}

In the considered low-pressure environment, heat transfer by radiation is expected to play a non negligible role $[7,8]$. In the present model, it was considered that the solid surfaces are 
opaque, that the radiation and the absorption occur in the same spectral range and that the absorption and radiation of the low pressure water vapour are negligible [21,31]. Thus, the heat flux by radiation $q_{r}$ can be described by the Stefan-Boltzmann equation [29,31]:

$$
q_{r}=F_{1 \rightarrow 2} \sigma\left(T_{1}^{4}-T_{2}^{4}\right)
$$

where $T_{1}$ and $T_{2}$ are the absolute temperatures of the surfaces 1 and 2 respectively, $\sigma$ is the Stefan-Boltzmann constant and $F_{1 \rightarrow 2}$ the visualization factor between the two surfaces under consideration.

The surface-to-surface radiation model proposed by COMSOL was used to evaluate the radiation heat transfer by the hemicube method. This method takes into account the shadowing effect in the system, automatically calculating the view factors for all the bodies present in the geometry. The surface-to-surface model results in very accurate computation, including all the possible contributions to radiation heat transfer, even if it remains timeconsuming.

Furthermore, a simplified radiation model was developed. In this model, only the main radiation contributions were considered, as schematized in Figure 3. Each part of the rail and vial surface was assumed to exchange by radiation with one of the imposed temperature surfaces (wall, shelves, ice interface). The visualization factors were estimated as for parallel plates $[29,31]$ :

$$
F_{1 \rightarrow 2}=\frac{1}{\frac{1}{e_{1}}+\frac{1}{e_{2}}-1}
$$

Equation 11

The internal walls of the vials were assumed to act as a black body. The radiation rays coming from the top shelf are eventually trapped by the internal vial walls after several reflections. Values of the visualisation factors used in the simplified radiation model are given in Table 2.

\subsection{Numerical solution}

The developed model was solved by means of Comsol Multiphysics 5.2 (COMSOL, Inc, Burlington, USA). This commercial software was ran on a PC, equipped with Intel(R) Core(TM) i7-490 CPUs, at $3.6 \mathrm{GHz}, 64-$ bits, with $32 \mathrm{~Gb}$ of RAM, under Windows 10. Governing equations were solved under steady-state condition by applying the finite-element 
method. The solution of the large linear system resulting from the linearization of the coupled equations was reached with the help of the Multifrontal Massively Parallel Sparse Direct Solver (MUMPS) [33]. The relative tolerance was set to $10^{-5}$. Numerical tests were based on non-structured meshing (tetrahedral elements).

\section{Results}

\subsection{Mesh and radiation resolution sensitivity analysis}

A sensitivity test was performed since the numerical solution of the problem depends on the resolution adopted in discretizing the equations. Regarding the mesh resolution used for discretizing the conduction equations, an increase of the number of elements by about $40 \%$ resulted in a weak impact on heat fluxes with a difference of maximum $0.2 \%$ (Table 3 ) for the different vials $(\mathrm{C}, \mathrm{E}, \mathrm{M})$. The increase of the angular discretization applied for radiation calculations (from 64 to 4096 streams) did not modify the predicted values of heat fluxes $(0.002 \%)$. COMSOL simulations were thus considered robust, and lower values of mesh elements (189 628) and radiation streams (64) were selected to reduce computation time.

\subsection{Model validation}

The model was validated based on sublimation experiments carried out at four chamber pressures $(4,6,9$ and $15 \mathrm{~Pa})$ and two shelf temperatures $\left(-40{ }^{\circ} \mathrm{C}\right.$ and $\left.0{ }^{\circ} \mathrm{C}\right)$ selected in the range typically used in freeze-drying of pharmaceuticals.

Figure 5 displays the comparison between the mean values of the experimental heat flow rates toward the ice-vapour interface and their standard deviations $(38,24$ and 100 vials in configuration $\mathrm{C}, \mathrm{E}$ and $\mathrm{M}$, respectively) and the model predictions for all the combinations of shelf temperature and chamber pressure tested. The agreement between measurements and model predictions was satisfactory. Deviations were less than $21 \%$ of the mean heat flow rate and close to the experimental coefficients of variation of each vial group. For the experiments performed at a shelf temperature of $0{ }^{\circ} \mathrm{C}$ and higher pressures ( 9 and $15 \mathrm{~Pa}$ ), the simulated heat flow rates of the vial $\mathrm{C}$ in contact with the rail appeared to be slightly overestimated with respect to the mean experimental value for both radiation models. Simulated and experimental heat flow rates of vial E not in contact with the rail showed a good agreement, as well as the simulated heat flow rates of the central vial, for all 6 combinations of applied operating conditions. These results were confirmed by the calculation of the relative mean error (RME) and the root mean square deviation (RMSD), presented Table 4. Simulated heat flow rates in vial $\mathrm{C}$ at high shelf temperature showed 
higher RME and RMSD values than vial E and M. However, the RME values remained below $11 \%$ for both the surface-to-surface model and the simplified model.

The quality of the models was also statistically assessed by the calculation of the coefficient of determination $R_{\text {pred }}^{2}$. Figure 6 presents predicted versus observed net heat flow rates for edge vials in contact (Vial C) and not in contact (Vial E) with the rail and for central vials (Vial M), both for the surface-to-surface (Figure $5 \mathrm{~A}, \mathrm{~B}$ and $\mathrm{C}$ ) and simplified radiation models (Figure $5 \mathrm{D}, \mathrm{E}$ and F). The distribution of the data around the 1:1 line and the value of $R_{\text {pred }}^{2}$ close to 1 confirmed the goodness of the simulations. The surface-to-surface model presented higher $R_{\text {pred }}^{2}$ values and appeared to better predict the heat flow rates in both edge and central vials than the simplified radiation model. However, the computational time was much longer for the surface-to-surface model (about $1 \mathrm{~h}$, physical memory $30 \mathrm{~GB}$ ) than for the simplified model (about 5 min, physical memory 6 GB).

These results confirm that the developed models represent well not only the usually considered heat transfer from the top and bottom shelves but also the border heat transfer from the wall and rail to the edge vials. Even if the results obtained from the two models were both accurate and comparable, it was decided to perform the further analysis using the surface-to-surface radiation model only.

\subsection{Temperature profile and heat fluxes distribution}

The developed 3D geometry allowed to visualize the temperature profile and the heat fluxes in the modelled system. An example is given in Figure 7 for the set of operating conditions ( 0 ${ }^{\circ} \mathrm{C}$ and $4 \mathrm{~Pa}$ and a wall temperature equal to $5.7{ }^{\circ} \mathrm{C}$ ). The temperature profile is represented by colour scale, whereas the heat flux distribution is represented by arrows whose length is proportional to the logarithm of the flux magnitude, to enhance the visualisation of small fluxes. Two different views of the system, showing the vial in contact (A) and not in contact (B) with the rail, are presented. The vial located at the center of the shelf (vial M) is also represented in Figure 7A.

When considering the central vial $\mathrm{M}$, product received heat fluxes from the bottom and the top shelves (upward and downward arrows). The temperature of the ice-vapour interface was equal to about $-50.7{ }^{\circ} \mathrm{C}$ (Equation 3). A small temperature difference was observed inside the product (e.g. about $1.5{ }^{\circ} \mathrm{C}$ difference between the ice bottom and the ice-vapour interface), which was in agreement with experimental results. In contrast, the temperature difference between the shelf and the vial bottom was close to $49{ }^{\circ} \mathrm{C}$. Due to the concave shape of the 
bottom, only a small portion of the vial bottom area was directly in contact with the shelf, whereas some gas was entrapped in the concavity between the shelf and the vial. Hence, the heat transfer was limited by the presence of the Knudsen layer, which caused an important temperature gradient between the shelf and the vial bottom, especially at low pressure as in this case $(4 \mathrm{~Pa})$. The downward arrows coming from the top shelf represented heat fluxes by conduction through the gas present the drying chamber and by radiation from the top shelf.

The edge vials ( $\mathrm{C}$ and $\mathrm{E}$ ) received additional lateral heat fluxes (highlighted by white rectangles in Figure 7) which resulted in an increase of the temperature of the vial lateral wall when increasing the proximity with the rail $\left(-48^{\circ} \mathrm{C}\right.$ for central vial $\mathrm{M},-47^{\circ} \mathrm{C}$ for vial $\mathrm{E}$ and $46{ }^{\circ} \mathrm{C}$ for vial $\mathrm{C}$ in contact with the rail). These lateral heat fluxes involved conduction through the gas present in the chamber and radiation from the rail and the wall.

Furthermore, the heat flux received by the rail exhibiting a temperature of $-23{ }^{\circ} \mathrm{C}$ depends on the direct contact between the rail bottom and the shelf (upward arrows from the bottom shelf) but also on the exposure to the chamber wall (lateral arrows) from which heat was transmitted by radiation and gas conduction.

\subsection{Relative importance of individual heat transfer mechanisms}

As shown in Figure 7, vials located in different positions on the shelf receive different heat transfer contributions from the wall, the rail, the shelves and the gas surrounding the vials through several heat transfer mechanisms (i.e. radiation, contact conduction, conduction through the gas). Understanding of the role played by each element of the drying chamber in the heat transfer could help reducing the "edge vial effect".

Thus, using the developed model, it was possible to evaluate the relative importance of four heat transfer contributions: (i) heat transfer from the bottom shelf by radiation, contact conduction and gas conduction (the latter related to the bottom concavity of the vial); (ii) heat transfer by conduction through the water vapour surrounding the vial (related to the top and the lateral side of the vial); (iii) heat transfer by radiation from the rail; (iv) heat transfer by radiation from the top shelf, the wall and the internal walls of the vial. Figure 8 displays the heat flow rates as well as the relative importance of these different elements calculated for a value of shelf temperature of $0{ }^{\circ} \mathrm{C}$ and the two extreme pressures in the explored range.

The heat flow rate from the bottom shelf was the same for all vials at a given pressure, but its relative importance in the total heat flow rate was higher in central vials than in edge vials. For example, at $4 \mathrm{~Pa}$ the relative importance of the heat transfer from the bottom shelf was about $54 \%$ for the central vial $\mathrm{M}$ but it decreases until about $47 \%$ for the edge vial $\mathrm{E}$ and 
about $36 \%$ for the edge vial C. Furthermore, the heat flow rate from the bottom shelf increased at higher pressure by about $70 \%$, because the heat transfer by conduction through the gas entrapped in the vial bottom curvature is a pressure dependent mechanism (§3.3.1). The conduction through the gas surrounding the vial appeared as a significant phenomenon and became the most important contribution to the heat transfer for the vials located at the border of the shelf. The edge vial $\mathrm{C}$ was particularly affected by the gas conduction, which contributes to the $50 \%$ of the total heat flow rate, due to the proximity to the rail.

The heat transfer by radiation from the rail, the wall and the top shelf had a relatively minor contribution to the total heat flow rate: from $5.6 \%$ to $14.3 \%$. The most important role was played by radiation from rail in vial C (about $10 \%$ at low pressure) and followed by vial $\mathrm{E}$ (about $6 \%$ ). This result is original, as the mainstream of the literature more or less implicitly ascribed the edge vial effect to radiation. The limited role of radiation is supported by some previous studies $[7,18]$, who found that the heat transfer difference between edge and central vials is not eliminated by the presence of a shielding rail.

\section{Conclusions}

The tri-dimensional, steady state mathematical model developed in this work successfully predicted the atypical heat transfer affecting the vials located at the periphery of the shelf in the freeze-drying process. The numerical solution of the model was validated with experimental results obtained in conditions relevant for pharmaceutical applications. The model made it possible to investigate the relative heat transfer contributions of the elements present in the drying chamber, i.e. wall, shelves and rail. In the range of operating conditions considered, the atypical heat transfer was mainly ascribed to gas conduction rather than radiation, as often stated in the literature. Furthermore, the radiation from the rail counts more than the radiation from the wall in the present configuration (height of the rail close to that of the vials). The use of rails made of a low emissivity and conductivity material could help in reducing the edge vial effect.

The developed model can be used to predict the heat flow rates in edge and central vials for different loading configurations and equipment characteristics, providing useful information for the freeze-drying cycle design and scale-up. 


\section{ACKNOWLEDGMENTS}

The authors would like to thank Benoit Moreau and Yves Mayeresse (GSK Vaccines) for reviewing this manuscript, Vincent Ronsse (technician) and Alain Philippart (operator) (GSK Vaccines) for their help in the data acquisition, and Victor Rousseau and Gwenael Davaud (AgroParisTech) for their help in developing the model.

\section{CONFLICT OF INTEREST}

Erwan Bourlès is an employee of the GSK group of companies. Bernadette Scutellà participated in a postgraduate $\mathrm{PhD}$ program at GSK Vaccines. Stephanie Passot, Fernanda Fonseca, Artemio Plana-Fattori, Denis Flick and Ioan Cristian Trelea report no financial conflicts of interest.

\section{FUNDING}

This work was funded by GlaxoSmithKline Biologicals S.A., under a Cooperative Research and Development Agreement with INRA (Institut National de la Recherche Agronomique) via the intermediary of the UMR (Unité Mixte de Recherche) GMPA (Génie et Microbiologie des Procédés Alimentaires) at the INRA Versailles-Grignon research centre.

\section{AUTHORS CONTRIBUTIONS}

All authors were involved in the conception of the model and design of the study. Bernadette Scutellà and Erwan Bourlès acquired the data. Bernadette Scutellà, Stephanie Passot, Erwan Bourlès, Fernanda Fonseca and Ioan Cristian Trelea analyzed and interpreted the experimental results. Bernadette Scutellà, Artemio Plana-Fattori, Denis Flick, and Ioan Cristian Trelea were involved in the model development. All authors were involved in drafting the manuscript or revising it critically for important intellectual content. All authors had full access to the data and approved the manuscript before it was submitted by the corresponding author. 


\section{Bibliography}

[1] T.A. Jennings, Lyophilization: introduction and basic principles, first ed., CRC Press, Englewood, CO, 1999.

[2] C. Ratti, Hot air and freeze-drying of high-value foods: a review, J. Food Eng. 49(4) 2001 311-319.

[3] W. Abdelwahed, G. Degobert, S. Stainmesse, H. Fessi, Freeze-drying of nanoparticles: Formulation, process and storage considerations, Adv. Drug Deliv. Rev. 58(15) 20061688 1713.

[4] X.C. Tang, M.J. Pikal, Design of freeze-drying processes for pharmaceuticals: practical advice, Pharm. Res. 21(2) 2004 191-200.

[5] F. Fonseca, S. Cenard, S. Passot, Freeze-Drying of Lactic Acid Bacteria, in: W.F. Wolkers, H. Oldenhof (Eds.), Cryopreservation and Freeze-Drying Protocols, Springer, New York, NY, 2015, pp. 477-488.

[6] M.J. Pikal, M. L. Roy, S. Shah, Mass and heat transfer in vial freeze-drying of pharmaceuticals: role of the vial, J. Pharm. Sci. 73(9) 1984 1224-1237.

[7] S. Rambhatla, M. J. Pikal, Heat and mass transfer scale-up issues during freeze-drying, I: atypical radiation and the edge vial effect, Aaps Pharmscitech. 4(2) 2003 22-31.

[8] M.J. Pikal, R. Bogner, V. Mudhivarthi, P. Sharma, P. Sane, Freeze-Drying Process Development and Scale-Up: Scale-Up of Edge Vial Versus Center Vial Heat Transfer Coefficients, Kv, J. Pharm. Sci. 105(11) 2016 3333-3343.

[9] B. Scutellà, S. Passot, E. Bourlés, F. Fonseca, I.C. Tréléa, How Vial Geometry Variability Influences Heat Transfer and Product Temperature During Freeze-Drying, J. Pharm. Sci. 106(3) 2017 770-778.

[10] X. Tang, S.L. Nail, M.J. Pikal, Evaluation of manometric temperature measurement, a process analytical technology tool for freeze-drying: Part I, product temperature measurement, AAPS PharmSciTech. 7(1) 2006 E95-E103.

[11] M.J. Pikal, S. Shah, The collapse temperature in freeze drying: Dependence on measurement methodology and rate of water removal from the glassy phase, Int. J. Pharm. 62(2-3) 1990 165-186.

[12] A.A. Barresi, S. Ghio, D. Fissore, R. Pisano, Freeze Drying of Pharmaceutical Excipients Close to Collapse Temperature: Influence of the Process Conditions on Process Time and Product Quality, Dry. Technol. 27(6) 2009 805-816.

[13] R. Johnson, L. Lewis, Freeze-drying protein formulations above their collapse temperatures: Possible issues and concerns, Am. Pharm. Rev. 14(3) 2011 50-54.

[14] D.E. Overcashier, T.W. Patapoff, C.C. Hsu, Lyophilization of protein formulations in vials: Investigation of the relationship between resistance to vapor flow during primary drying and small-scale product collapse, J. Pharm. Sci. 88(7) 1999 688-695. 
[15] S. Passot, F. Fonseca, N. Barbouche, M. Marin, M. Alarcon-Lorca, D. Rolland, M. Rapaud, Effect of Product Temperature During Primary Drying on the Long-Term Stability of Lyophilized Proteins, Pharm. Dev. Technol. 12(6) 2007 543-553.

[16] M.J. Pikal, Use of laboratory data in freeze drying process design: heat and mass transfer coefficients and the computer simulation of freeze drying, J. Parenter. Sci. Technol. Publ. Parenter. Drug Assoc. 39(3) 1985 115-139.

[17] M.J. Millman, A.I. Liapis, J.M. Marchello, An analysis of the lyophilization process using a sorption-sublimation model and various operational policies, AIChE J. 31(10) 1985 $1594-1604$.

[18] K.H. Gan, R. Bruttini, O.K. Crosser, A.I. Liapis, Freeze-drying of pharmaceuticals in vials on trays: effects of drying chamber wall temperature and tray side on lyophilization performance, Int. J. Heat Mass Transf. 48(9) 2005 1675-1687.

[19] S.A. Velardi, A.A. Barresi, Development of simplified models for the freeze-drying process and investigation of the optimal operating conditions, Chem. Eng. Res. Des. 86(1) 2008 9-22.

[20] A. Hottot, R. Peczalski, S. Vessot, J. Andrieu, Freeze-Drying of Pharmaceutical Proteins in Vials: Modeling of Freezing and Sublimation Steps, Dry. Technol. 24(5) 2006 561-570.

[21] M. Brülls, A. Rasmuson, Heat transfer in vial lyophilization, Int. J. Pharm. 246(1) 2002 $1-16$.

[22] S. Zhai, H. Su, R. Taylor, N.K.H. Slater, Pure ice sublimation within vials in a laboratory lyophiliser; comparison of theory with experiment, Chem. Eng. Sci. 60(4) 2005 $1167-1176$.

[23] I.C. Trelea, S. Passot, F. Fonseca, M. Marin, An Interactive Tool for the Optimization of Freeze-Drying Cycles Based on Quality Criteria, Dry. Technol. 25(5) 2007 741-51.

[24] Y. Liu, Y. Zhao, X. Feng, Exergy analysis for a freeze-drying process, Appl. Therm. Eng. 28(7) 2008 675-690.

[25] P. Sheehan, A.I. Liapis, Modeling of the primary and secondary drying stages of the freeze drying of pharmaceutical products in vials: Numerical results obtained from the solution of a dynamic and spatially multi operational policies, Biotechnol. Bioeng. 60(6) 1998 712-728.

-differesesional Iyophiliza

[26] J. Monchau, Y. Candau, L. Ibos, Device for measuring the emissivity or reflectivity of a surface, 2013, Patent: FR20120051476.

[27] R. Pisano, A.A. Barresi, D. Fissore, Heat Transfer in Freeze-Drying Apparatus, in: M.A. dos Santos Bernardes (Ed.), Developments in Heat Transfer, InTech, Rijeka, Croatia, 2011, pp. 91-114.

[28] R. Pisano, D. Fissore, A.A. Barresi, P. Brayard, P. Chouvenc, B. Woinet. Quality by design: optimization of a freeze-drying cycle via design space in case of heterogeneous drying behavior and influence of the freezing protocol, Pharm. Dev. Technol. 18(1) 2013 280-295. 
[29] M.J. Pikal, Heat and mass transfer in low pressure gases: applications to freeze drying, in Drugs Pharm. Sci. 1022000 611-686.

[30] A. Ganguly, S.L. Nail, A. Alexeenko, Experimental Determination of the Key Heat Transfer Mechanisms in Pharmaceutical Freeze-Drying, J. Pharm. Sci. 102(5) 2013 16101625.

[31] R.B. Bird, W.E. Stewart, E.N. Lightfoot, Transport phenomena, second ed., Wiley International, New York, NY, 2002.

[32] S. Dushman, Scientific foundations of vacuum technique, second ed., Wiley, New York, NY, 1962.

[33] P.R. Amestoy, I.S. Duff, J.Y. L'Excellent, J. Koster, MUMPS: a general purpose distributed memory sparse solver, in: T. Sørevik, F. Manne, A.H. Gebremedhin, R. Moe (Eds.), Applied Parallel Computing. New Paradigms for HPC in Industry and Academia. PARA 2000. Lecture Notes in Computer Science, vol 1947, Springer, Berlin, 2001, pp. 121-130.

[34] R.H. Perry, D.W. Green, J.O. Maloney (Eds.), Perry's chemical engineers' handbook, seventh ed., McGraw-Hill, New York, 1997.

[35] W.M. Haynes (Ed.), CRC handbook of chemistry and physics, ninety-fifth ed., CRC Press, New York, 2014.

[36] S. Fukusako, Thermophysical properties of ice, snow, and sea ice, Int. J. Thermophys. 11(2) $1990353-372$.

[37] K. M. Keener, Heat transfer, in: D.R. Heldman (Ed.), Encyclopedia of Agricultural, Food, and Biological Engineering, second ed., Taylor and Francis, New York, 2010. 


\section{Tables}

Table 1: Relevant thermal properties and constants used in the model

\begin{tabular}{|c|c|c|c|}
\hline Property & Symbol & Value & Reference \\
\hline Stefan-Boltzmann constant & $\sigma$ & $5.710^{-8} \frac{W}{m^{2} K^{4}}$ & \multirow{4}{*}[34]{} \\
\hline Latent heat of ice sublimation & $\Delta H$ & $2.810^{6} \frac{\mathrm{J}}{\mathrm{kg}}$ & \\
\hline Thermal conductivity of the rail stainless steel & $\lambda_{R}$ & $16.5 \frac{W}{m K}$ & \\
\hline Thermal conductivity of the vial glass & $\lambda_{G}$ & $1.1 \frac{W}{m K}$ & \\
\hline $\begin{array}{l}\text { Thermal conductivity of the water vapour at } \\
\text { atmospheric pressure }\end{array}$ & $\lambda_{w}$ & $2.510^{-2} \frac{\mathrm{W}}{\mathrm{mK}}$ & [35] \\
\hline Thermal conductivity of the ice & $\lambda_{I}$ & $2.2 \frac{W}{m K}$ & {$[36]$} \\
\hline Ice emissivity & $\varepsilon_{I}$ & 0.98 & {$[37]$} \\
\hline Vial glass emissivity & $\varepsilon_{V}$ & 0.78 & [9] \\
\hline Rail stainless steel emissivity & $\varepsilon_{R}$ & 0.14 & \multirow{5}{*}{$\begin{array}{l}\text { Measured } \\
\text { in this } \\
\text { study }\end{array}$} \\
\hline Shelf stainless steel emissivity & $\varepsilon_{S}$ & 0.18 & \\
\hline Wall stainless steel emissivity & $\varepsilon_{W}$ & 0.13 & \\
\hline $\begin{array}{l}\text { Temperature of the wall when } \\
\qquad T_{S}=0^{\circ} \mathrm{C}\end{array}$ & \multirow{2}{*}{$T_{W}$} & $5.7^{\circ} \mathrm{C}$ & \\
\hline $\begin{array}{l}\text { Temperature of the wall when } \\
\qquad T_{S}=-40{ }^{\circ} \mathrm{C}\end{array}$ & & $0.9^{\circ} \mathrm{C}$ & \\
\hline
\end{tabular}


Table 2: Relevant model parameters for heat transfer

\begin{tabular}{|c|c|c|c|}
\hline Parameter & Symbol & Value & Reference \\
\hline $\begin{array}{l}\text { Free molecular flow heat transfer } \\
\text { coefficient }\end{array}$ & $\Lambda_{o}$ & $1.99 \frac{W}{m^{2} K P a}$ & [29] \\
\hline $\begin{array}{l}\text { Semi-empirical constant } \\
\text { (equal to } C_{2} / \Lambda_{o} \text { in Scutellà et al. [9]) }\end{array}$ & $\alpha$ & 0.34 & \multirow{2}{*}{$\begin{array}{c}\text { Calculated } \\
\text { from data } \\
\text { presented in } \\
{[9]}\end{array}$} \\
\hline $\begin{array}{l}\text { Heat transfer coefficient by } \\
\text { conduction shelf-vial }\end{array}$ & $K_{c c_{V}}$ & $25.80 \frac{W}{m^{2} K}$ & \\
\hline $\begin{array}{l}\text { Heat transfer coefficient by } \\
\text { conduction shelf-rail }\end{array}$ & $K_{c c_{R}}$ & $10 \frac{W}{m^{2} K}$ & \multirow{6}{*}{$\begin{array}{l}\text { Evaluated in } \\
\text { this study }\end{array}$} \\
\hline Visualization factor wall-rail $^{(a)}$ & $F_{W \rightarrow R}$ & 0.07 & \\
\hline Visualization factor wall-vial $^{(\mathrm{a})}$ & $F_{W \rightarrow V}$ & 0.12 & \\
\hline Visualization factor rail-vial $^{(a)}$ & $F_{R \rightarrow V}$ & 0.13 & \\
\hline Visualization factor shelf-vial $^{(a)}$ & $F_{T S \rightarrow V}, F_{B S \rightarrow V}$ & 0.17 & \\
\hline Visualization factor vial-ice ${ }^{(b)}$ & $F_{I \rightarrow V}$ & 0.98 & \\
\hline
\end{tabular}


Table 3: Heat flow rates at the ice sublimation interface in vials $C, E, M$ for a chamber pressure of $4 \mathrm{~Pa}$ and a shelf temperature of $0{ }^{\circ} \mathrm{C}$ versus the number of mesh elements and the maximum element size evaluated for a radiation resolution of 64 streams.

\begin{tabular}{|c|c|c|c|c|}
\hline \multirow{2}{*}{$\begin{array}{c}\text { Number of } \\
\text { mesh elements }\end{array}$} & $\begin{array}{c}\text { Maximum } \\
\text { element size } \\
{[\mathrm{m}]}\end{array}$ & Vial C & Vial E & Vial M \\
\cline { 3 - 5 } & 0.0134 & 0.1219 & 0.09522 & 0.08105 \\
\hline 189628 & 0.0107 & 0.1222 & 0.09525 & 0.08108 \\
\hline 259433 & $(-0.2 \%)$ & $(-0.03 \%)$ & $(-0.04 \%)$ \\
\hline
\end{tabular}


Table 4: Relative mean error (RME) and the root mean square deviation (RMSD) for the surface-to-surface and simplified radiation models considering the vials $\mathrm{C}, \mathrm{E}, \mathrm{M}$.

\begin{tabular}{|c|c|c|c|c|}
\hline & \multicolumn{2}{|c|}{$\begin{array}{c}c \mid \\
\%\end{array}$} & \multicolumn{2}{c|}{$[\mathrm{W}]$} \\
\hline \multirow{2}{*}{} & $\begin{array}{c}\text { Surface-to-Surface } \\
\text { model }\end{array}$ & $\begin{array}{c}\text { Simplified } \\
\text { model }\end{array}$ & $\begin{array}{c}\text { Surface-to-Surface } \\
\text { model }\end{array}$ & $\begin{array}{c}\text { Simplified } \\
\text { model }\end{array}$ \\
\hline Vial C & 11 & 11 & 0.014 & 0.016 \\
\hline Vial $E$ & 9 & 7 & 0.007 & 0.008 \\
\hline Vial M & 4 & 11 & 0.003 & 0.009 \\
\hline
\end{tabular}




\section{Figures}

A

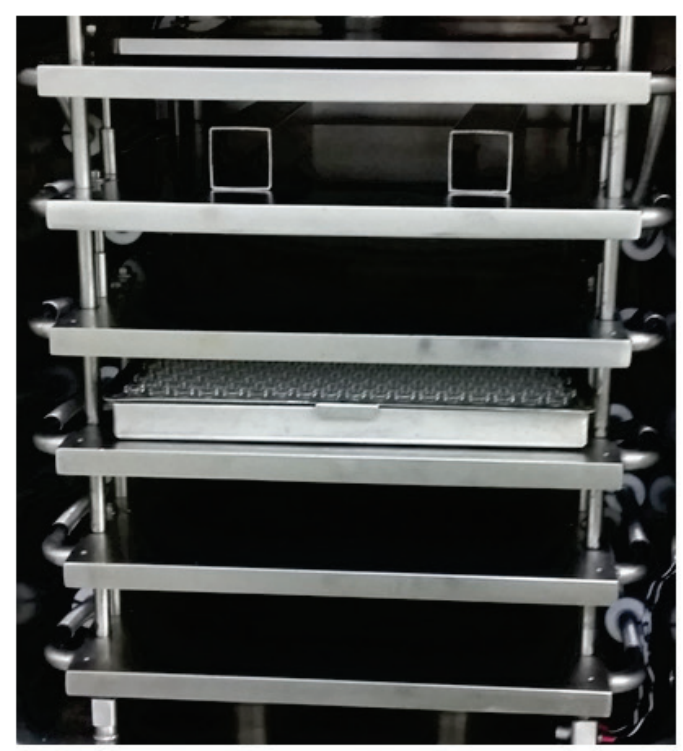

B

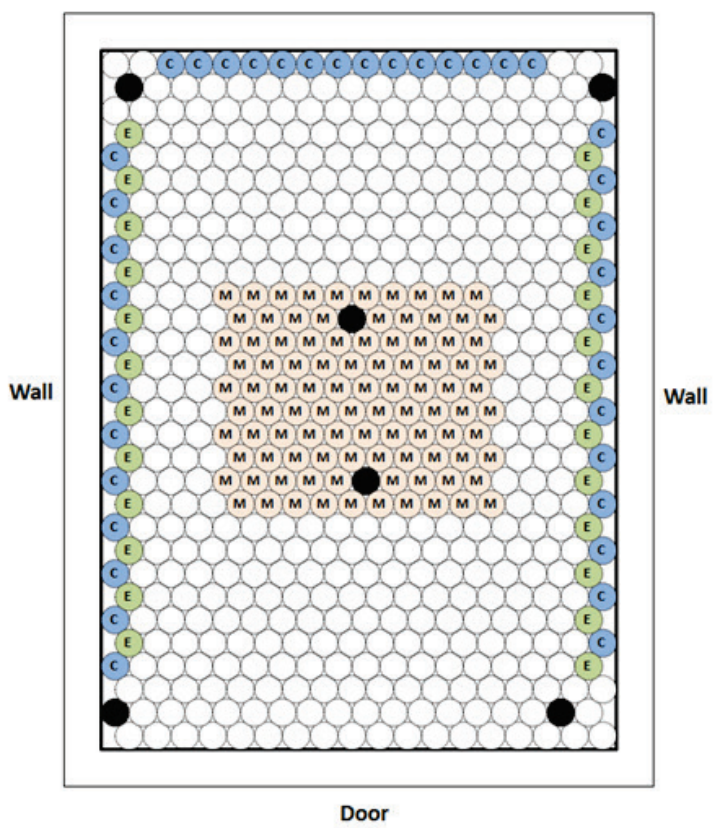

Figure 1: Arrangement of the vials on the shelf in the drying chamber: (A) real view of the chamber; (B) position of the vials weighted in the gravimetric method. Marker " $\mathrm{C}$ " indicate vials in contact with the rail, "E" vials exposed but not in contact with the rail and "M" central vials. Black circles represent vials in which Tempris sensors where placed to monitor ice temperature. 


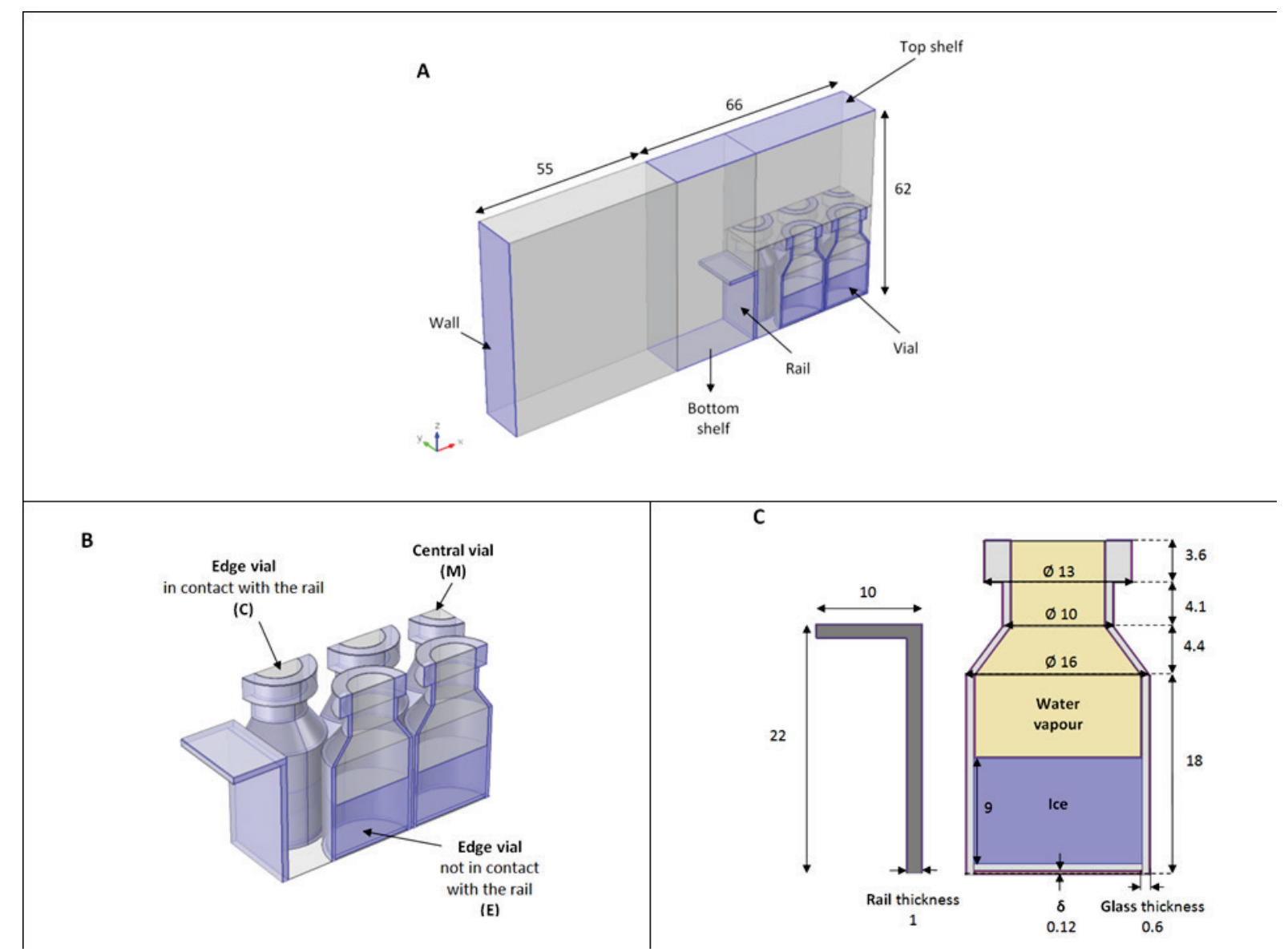

Figure 2: Three views of the built geometry with relevant dimensions (in mm): (A) global view of the vials, shelves, rail and wall; (B) zoom on the vials and rail system and classification of the vials; $(\mathrm{C})$ detail of the vial and rail geometry. 


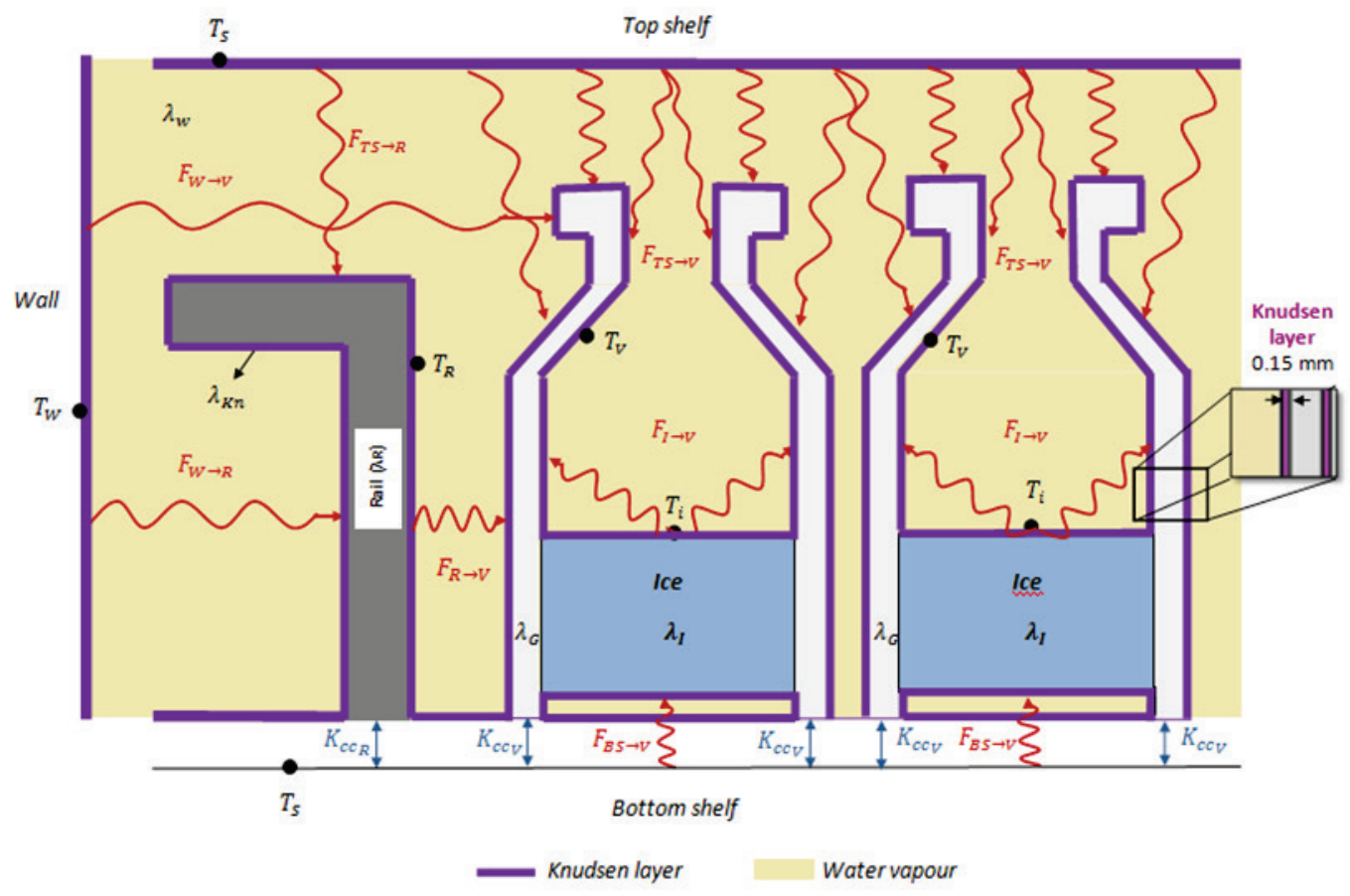

Figure 3: Schematic representation (not in scale) of the main heat transfer mechanisms, corresponding coefficients and relevant body temperatures in the analyzed system. Radiation mechanisms considered in the simplified model are shown $(\S 3.5)$. 


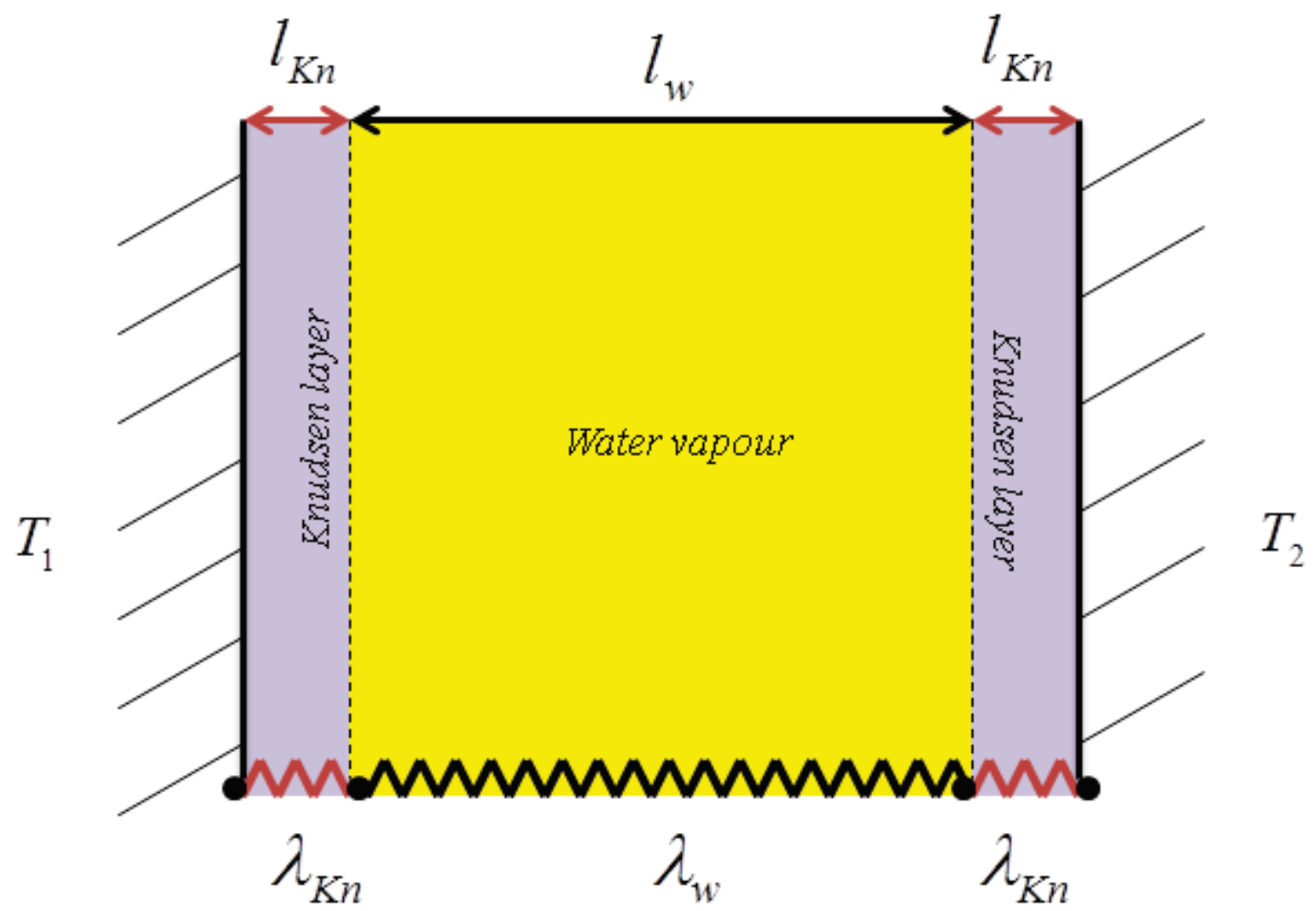

Figure 4: Schematic representation of the heat transfer resistances in the gas, as given by Equation 6. 
$0^{\circ} \mathrm{C}$

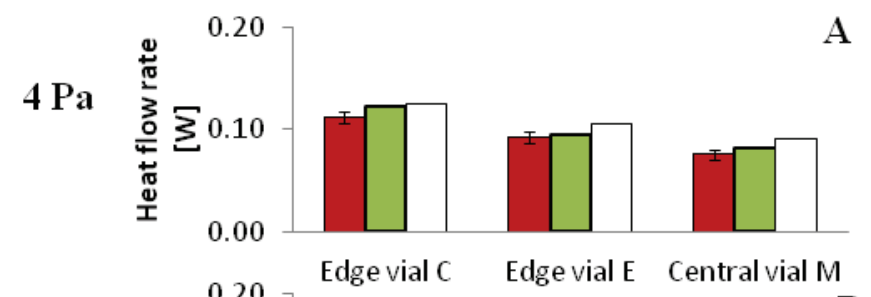

$6 \mathrm{~Pa}$

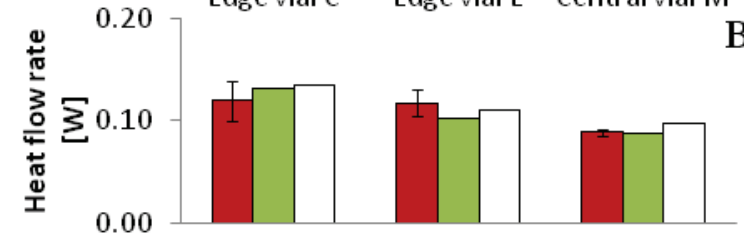

$9 \mathrm{~Pa}$

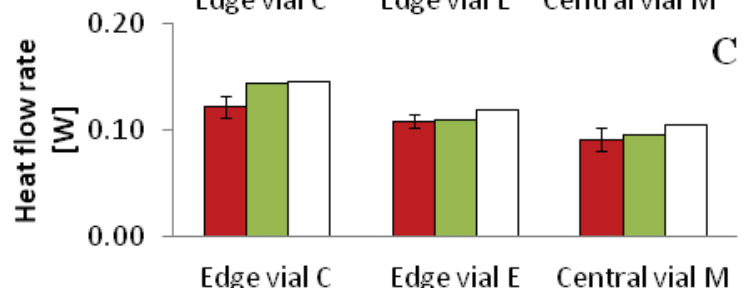

$15 \mathrm{~Pa}$

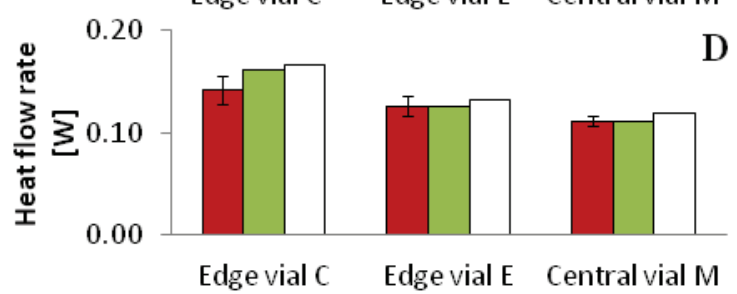

$-40^{\circ} \mathrm{C}$

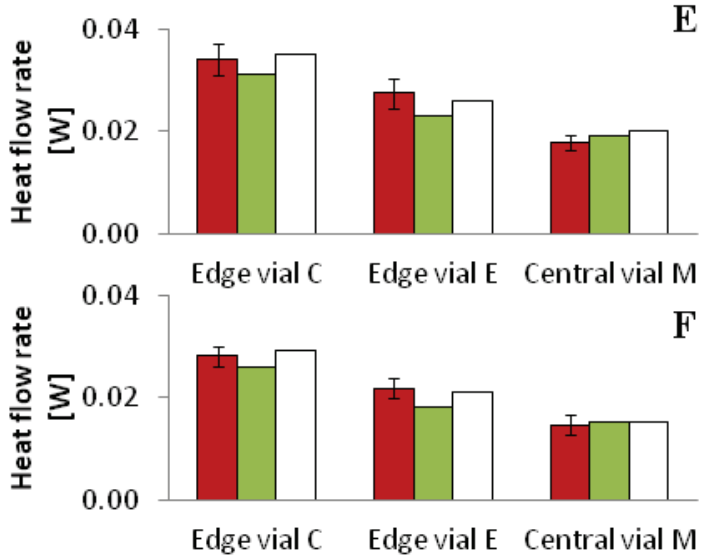

$\mathrm{C}$

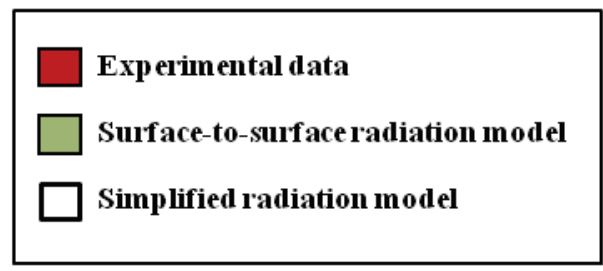

Figure 5: Comparison of experimental and simulated heat flow rates for edge vial in contact (C) and not in contact (E) with the rail and for central vial (M). Several combinations of shelf temperatures $\left(-40^{\circ} \mathrm{C}\right.$ and $\left.0{ }^{\circ} \mathrm{C}\right)$ and chamber pressures $(4,6,9,15 \mathrm{~Pa})$ were tested. Error bars in experimental data represent standard deviations. 

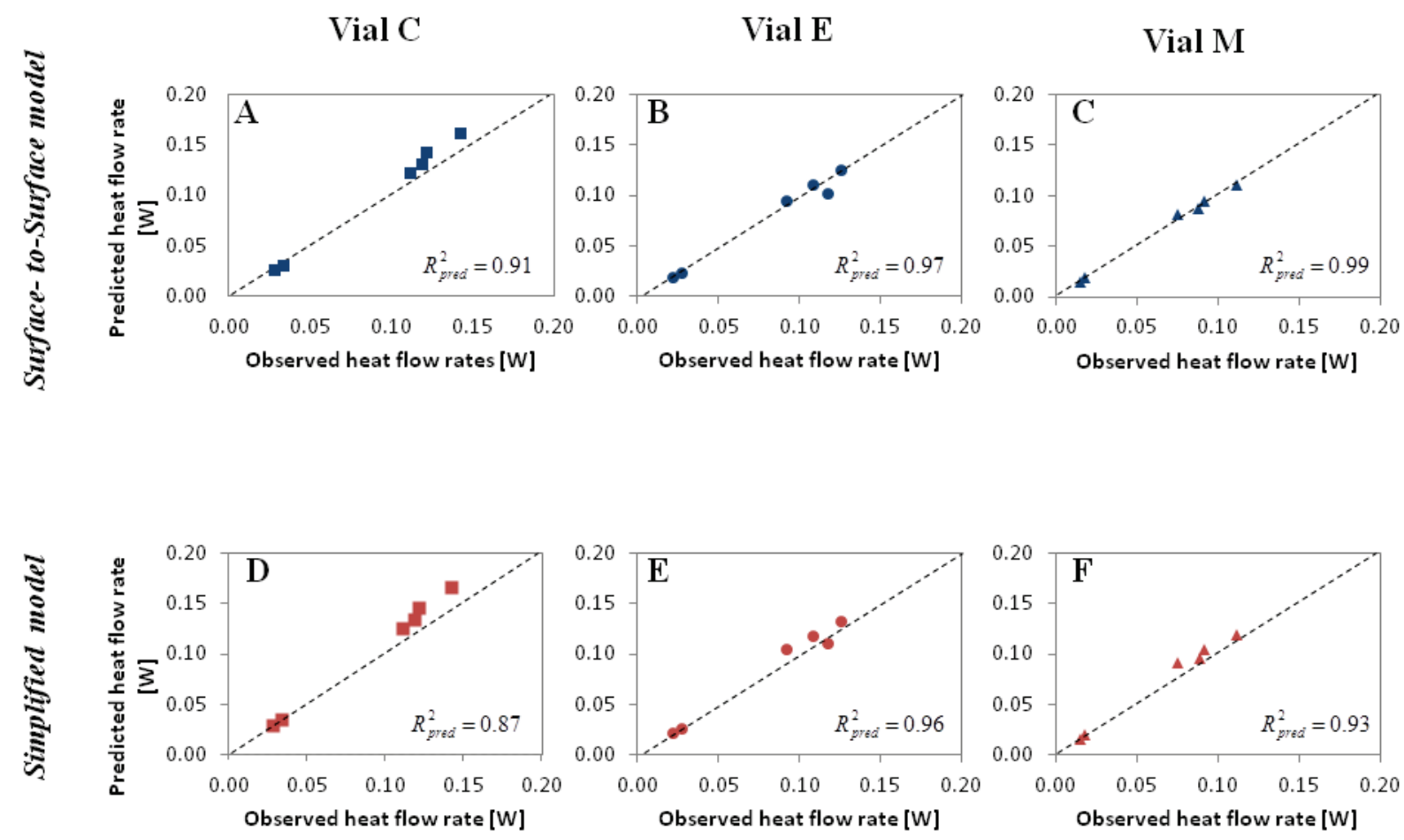

Figure 6: Predicted vs. observed heat flow rates for both surface-to-surface (A, B, C) and simplified radiation models (D, E, F). Square, circle and triangle markers represent respectively the edge vials $\mathrm{C}, \mathrm{E}$ and the central vials $\mathrm{M}$. The 1:1 dotted line represents perfect agreement between predicted and observed value. The values of the coefficient of determination $\left(R_{\text {pred }}^{2}\right)$ are reported on the figure. 
A

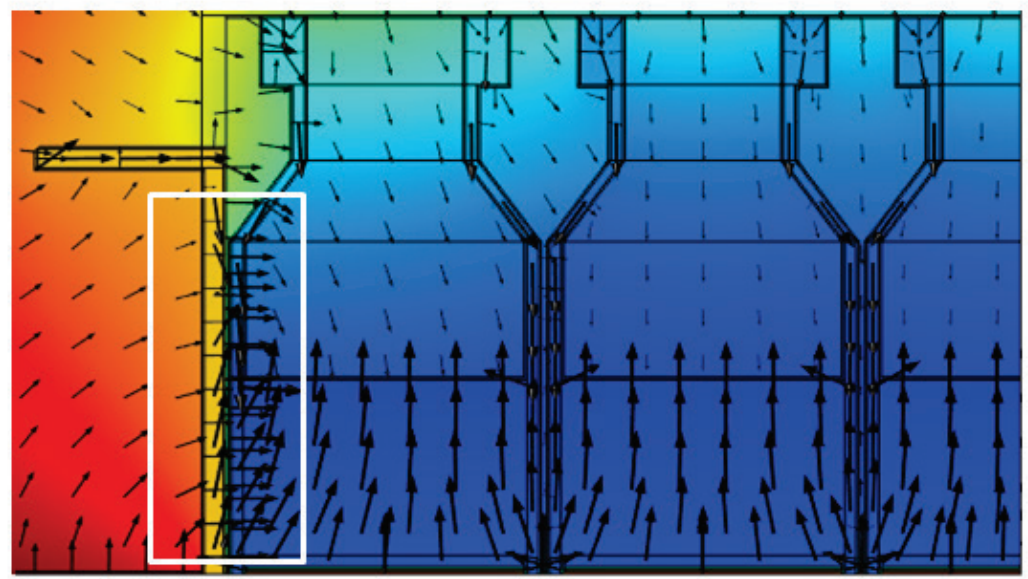

Vial C

Vial M

B

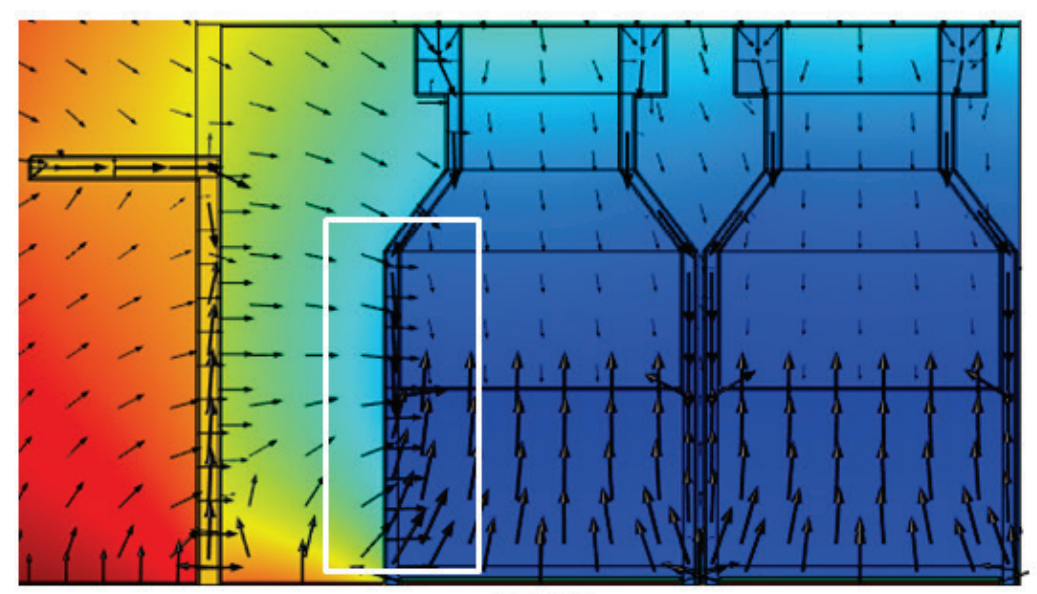

Vial E

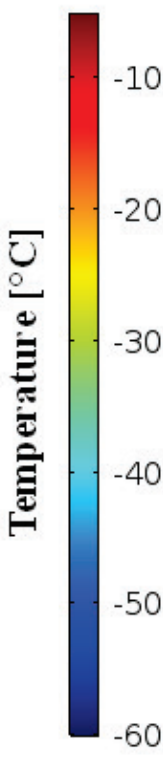

Figure 7: Temperature profiles and heat fluxes in the vial in contact (view A) and not in contact (view B) with the rail at a shelf temperature of $0{ }^{\circ} \mathrm{C}$ and a chamber pressure of $4 \mathrm{~Pa}$. White rectangles indicate the lateral heat fluxes in edge vials $\mathrm{C}$ and $\mathrm{E}$. Arrow length indicates flux magnitude on a logarithmic scale, to improve the visualisation of smaller fluxes from top, wall and rail. 

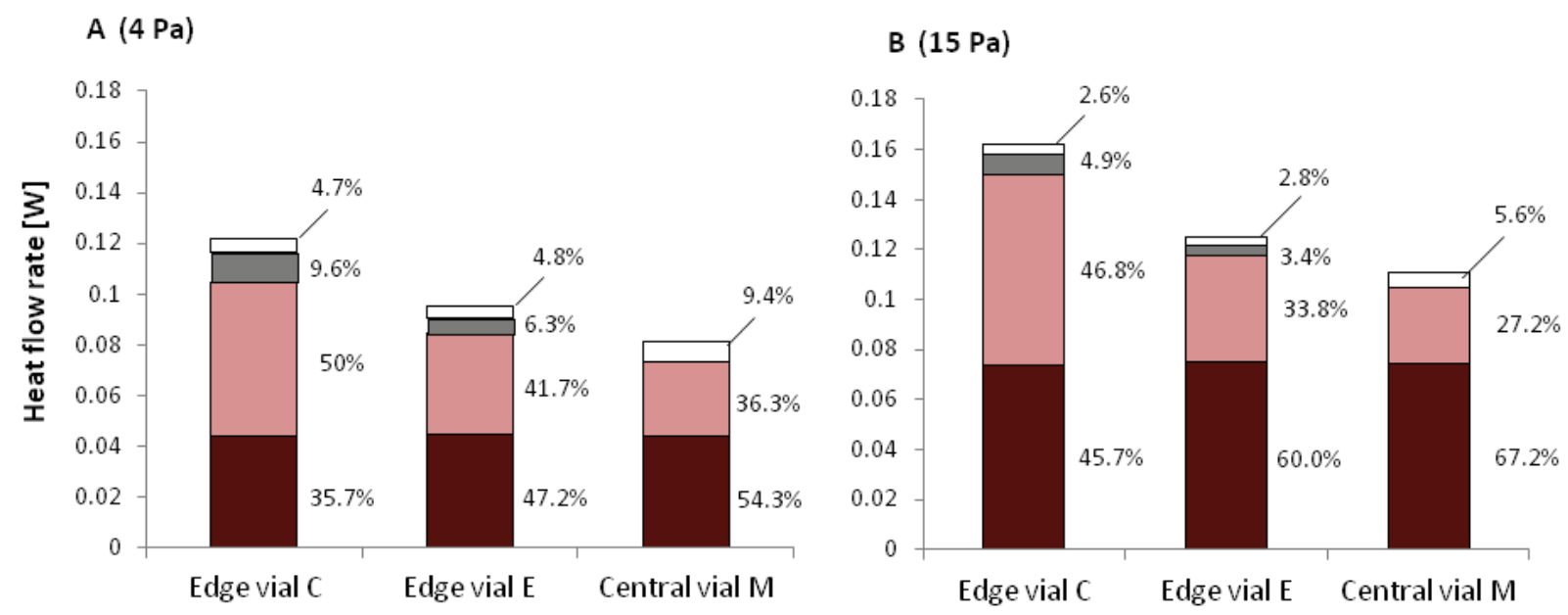

$\square$ Radiation from the top shelf, the chamber wall and the internal walls of the vial

$\square$ Radiation from the rail

$\square$ Conduction through the gas surrounding the vial

Heat transfer from the bottom shelf

Figure 8: Heat flow rate contributions and their relative importance (in \%) of the single heat transfer mechanisms to the total heat transfer. Results are shown for edge vials in contact (C) and not in contact (E) with the rail and in central vial (M) at a shelf temperature of $0{ }^{\circ} \mathrm{C}$ and two different pressures (4 and $15 \mathrm{~Pa})$. 